\title{
Embryonic Cerebrospinal Fluid Collaborates With the Isthmic Organizer To Regulate Mesencephalic Gene Expression
}

\author{
Carolina Parada, ${ }^{1}$ Cristina Martín, ${ }^{2}$ María I. Alonso, ${ }^{2,3}$ José A. Moro, ${ }^{2,3}$ \\ David Bueno, ${ }^{1 \star}$ and Angel Gato ${ }^{2,3}$ \\ ${ }^{1}$ Departament de Genètica, Facultat de Biologia, Universitat de Barcelona, Barcelona, Catalonia, Spain \\ ${ }^{2}$ Departamento de Anatomía y Radiología, Facultad de Medicina, Universidad de Valladolid, \\ Valladolid, Spain \\ ${ }^{3}$ Laboratorio de Desarrollo y Teratología del Sistema Nervioso, Instituto de Neurociencias de \\ Castilla y León, Castilla y León, Spain
}

Early in development, the behavior of neuroepithelial cells is controlled by several factors acting in a developmentally regulated manner. Recently it has been shown that diffusible factors contained within embryonic cerebrospinal fluid (CSF) promote neuroepithelial cell survival, proliferation, and neurogenesis in mesencephalic explants lacking any known organizing center. In this paper, we show that mesencephalic and mesencephalic + isthmic organizer explants cultured only with basal medium do not express the typically expressed mesencephalic or isthmic organizer genes analyzed (otx2 and fgf8, respectively) and that mesencephalic explants cultured with embryonic CSF-supplemented medium do effect such expression, although they exhibit an altered pattern of gene expression, including ectopic shh expression domains. Other trophic sources that are able to maintain normal neuroepithelial cell behavior, i.e., fibroblast growth factor-2, fail to activate this ectopic shh expression. Conversely, the expression pattern of the analyzed genes in mesencephalic + isthmic organizer explants cultured with embryonic cerebrospinal fluid-supplemented medium mimics the pattern for control embryos developed in ovo. We demonstrate that embryonic CSF collaborates with the isthmic organizer in regulation of the expression pattern of some characteristic neuroectodermal genes during early stages of central nervous system (CNS) development, and we suggest that this collaboration is not restricted to the maintenance of neuroepithelial cell survival. Data reported in this paper corroborate the hypothesis that factors contained within embryonic CSF contribute to the patterning of the CNS during early embryonic development. ๑ 2005 Wiley-Liss, Inc.

Key words: brain development; neuroepithelial organotypic culture; isthmic organizer; embryonic cerebrospinal fluid; gene expression
Development of the central nervous system (CNS) involves the simultaneous and interdependent action of several developmental mechanisms. The pattern and dynamics of gene expression in the brain vesicles, as well as its role in the patterning of CNS structures, are known for a number of genes. Diffusible molecules, such as growth factors and morphogens, secreted locally by organizing centers, also contribute to the establishment of positional identities and to the patterning of CNS structures, by controlling neighboring cells in an autocrine/paracrine manner (Yamada et al., 1991; Placzek et al., 1991, 1993; Roelink et al., 1994; Crossley and Martin, 1995; Bueno et al., 1996a; Crossley et al., 1996; Shamim et al., 1999; Vaccarino et al., 1999a,b; Toresson et al., 2000; Garda et al., 2001; Panchision and McKay, 2002).

It has been reported that fibroblast growth factor- 8 (FGF8) secreted from the isthmic organizer (IsO) contributes to the patterning of gene expression in the midand hindbrain by inducing the expression of en1, en2, pax2, and pax5 and repressing otx2 (Liu et al., 1999; Ye et al., 2001). Most of these genes interact with each other to control the pattern of the cephalic vesicles and to maintain or refine the morphogenetic activity of the IsO ( $\mathrm{Li}$ and Joyner, 2001). For example, en 1 induces foff in the IsO; otx 2 coordinates positioning of shh and $f g f 8$ expression; FGF8 is the active diffusible molecule for

The last two authors contributed equally to this work.

^Correspondence to: David Bueno, Departament de Genètica, Facultat de Biologia, Universitat de Barcelona, Av. Diagonal 645, E-08028 Barcelona, Catalonia, Spain. E-mail: dbueno@ub.edu

Received 13 April 2005; Revised 28 June 2005; Accepted 28 June 2005

Published online 22 September 2005 in Wiley InterScience (www. interscience.wiley.com). DOI: 10.1002/jnr.20618 
isthmic morphogenetic activity; and FGF8 also induces the formation of ectopic IsOs (Martínez et al., 1999; Shamin et al., 1999; Joyner et al., 2000; Martínez, 2001; Puelles et al., 2003, 2004).

No reported experiments focusing on CNS development, which include tissue transplantation, implantation of beads soaked in morphogens or growth factors, and electroporation of constructs, take into account the possible effect of embryonic cerebrospinal fluid (E-CSF) on neuroepithelial cell behavior. E-CSF is a complex fluid that contains various protein fractions (Gato et al., 2004; Parada et al., 2005). It completely fills the brain vesicles and is in close contact with the apical pole of neuroepithelial cells. In vivo this fluid generates an expansive force on neuroepithelial walls; its removal causes brain vesicle collapse (for review see Miyan et al., 2003). At fetal and early posthatching stages, CSF also influences brain development and cortical histogenesis (Mashayekhi et al., 2002; Owen-Lynch et al., 2003).

Several reports indicate that the neuroepithelium behaves autonomously, except for the known effect of the notochord on the floor plate of the neural tube (Echelard et al., 1993; Martí et al., 1995; Vaccarino et al., 1999b). However, experiments performed in vitro on mesencephalic explants of chick embryos at HH20HH23 (Hamburger and Hamilton, 1951) have demonstrated that mesencephalic neuroectodermal cells are not completely autonomous and that diffusible molecules contained within E-CSF contribute to the regulation of their survival, proliferation, and neurogenesis (Gato et al., 2005).

The aim of this study is to determine whether ECSF also contributes to the regulation of neuroepithelial gene expression. We used an organotypic culture technique previously validated by Gato et al. (2005). This technique enabled us to analyze gene expression in a simplified system, in which the explants maintain the neuroepithelial architecture with its intrinsic cell-cell interactions, and to monitor the influence exerted by other embryonic structures or tissues, such as the $\mathrm{IsO}$ or the E-CSF, regardless of brain collapse. We tested whether neuroepithelial gene expression is autonomous or depends on other stimuli, and we analyzed the relative contribution of E-CSF and the IsO to the regulation of neuroepithelial gene expression in these organotypic cultures. Here we demonstrate that E-CSF is needed for the IsO to regulate the expression pattern of some neuroectodermal genes during early stages of CNS development, and we suggest that this collaboration goes beyond the known role for E-CSF in neuroepithelial cell survival.

\section{MATERIALS AND METHODS}

\section{Obtaining E-CSF}

Fertile chicken eggs were incubated at $38^{\circ} \mathrm{C}$ in a humid atmosphere to obtain chick embryos at developmental stage HH24 (Hamburger and Hamilton, 1951). After the embryos were dissected out of extraembryonic membranes, the E-CSF was aspirated as described by Gato et al. (2004).

\section{Organotypic Cultures}

Organotypic cultures of both mesencephalic neuroectodermal explants (dorsal mesencephalon) and mesencephalic + $\mathrm{IsO}$ neuroectodermal explants were grown as described by Gato et al. (2005). Consequently, the explants comprised either the roof plate of the midbrain and the neuroepithelium lateral to it or alternatively the roof plate of the midbrain, the neuroepithelium lateral to it, and the midbrain/hindbrain isthmus. Neuroepithelial explants were conducted in vitro for $24 \mathrm{hr}$, from HH20 to HH23. The explants were peripherally fixed to small rectangles of Millipore filters $(0.8 \mu \mathrm{m}$ pore size $)$ with a tungsten needle as previously described (Gato et al., 2005). They were cultured with a chemically defined serumfree medium (basal medium; DMEM:F12; Sigma, St. Louis, MO) supplemented with $1 \%$ ascorbic acid, or alternatively supplemented with various additives, at $37^{\circ} \mathrm{C}$ with $5 \% \mathrm{CO}_{2}$. The following additives were added to the basal medium: E-CSF at $1 / 7$ v/v (Gato et al., 2005); FGF2 at $50 \mathrm{ng} / \mu \mathrm{l}$ [Sigma; human recombinant; as it has previously been reported that this medium is able to support proliferation and differentiation of neural precursors (Tropepe et al., 1999; Panchision and McKay, 2002)]; FGF8 at 50 ng/ $\mu$ l [Sigma; human recombinant FGF8b; as it is known to be the active diffusible molecule for morphogenetic IsO activity (Martínez et al., 1999; Martínez, 2001)]; or E-CSF (1/7 v/v) + FGF8 (at $50 \mathrm{ng} / \mu \mathrm{l}, 5 \mathrm{ng} / \mu \mathrm{l}$, or $0.5 \mathrm{ng} / \mu \mathrm{l})$.

\section{In Situ Hybridization}

RNA in situ hybridization on whole-mount control embryos or on neuroepithelial explants was performed as described by Bueno et al. (1996b) either for one- or twoprobe development, by using single-stranded digoxigenin (DIG) or fluorescein (FITC) UTP-labelled (Boehringer Mannheim, Mannheim, Germany) antisense riboprobes. Ten explants were hybridized with each probe for each culture condition. Fgf8 riboprobe (from G. Martin; EcoRI digestion and T3 transcription), shh riboprobe (from A. Pierani; HindIII digestion and T3 transcription), otx2 riboprobe (from G. Martin; EcoRI digestion and T3 transcription), pax2 riboprobe (from P. Gruss; XbaI digestion and T3 transcription), and en 1 riboprobe (from G. Martin; EcoRI digestion and T3 transcription) were synthesized by using standard protocols. Prior to hybridization, control embryos maintained in ovo until HH23 were cut sagittally into two halves to facilitate hybridization and to avoid trapping of reagents in the cephalic cavities. For HH20 controls, mesencephalic and mesencephalic $+\mathrm{IsO}$ explants were processed for in situ hybridization just after fixing them to the Millipore filter (see above). For double in situ hybridization, both probes were hybridized simultaneously. The probes were detected by incubating either the whole-mount embryos or the explants overnight at room temperature (RT) with anti-DIG antibody (for one-probe development) or sequentially with antifluorescein isothiocyanate (FITC) and anti-DIG antibodies (for two-probe development) conjugated with alkaline phosphatase $(1 / 2,000$; Boehringer Mannheim). In situ hybridization was developed with NBT/BCIP (Boehringer Mannheim) for one-probe development or sequentially with $\mathrm{NBT} / \mathrm{BCIP}$ and fast red 
tablets (Roche, Indianapolis, IN) for two-probe development, according to standard protocols. Because of peripheral damage to the explants during experimental manipulation to avoid their detachment from the filter, gene expression on the periphery of the tissue was not evaluated. This area usually darkened, probably because of trapping of reagents, so to standardize results the study took into account only the central area of the explants. For viewing and photography of the control embryos and the explants after one-probe development, we used a Stemi V6 stereomicroscope (Zeiss). For viewing and photography of the explants after two-probe development, we used an MLFZIII stereomicroscope (Leica) equipped with epifluorescence. Images for NBT/BCIP staining were captured under visible light, and images for fast red staining were captured with a rhodamine filter set. Both images were merged in Adobe Photoshop.

\section{Immunohistochemistry and BrdU Incorporation}

To detect cell survival, we monitored active caspase-3 immunostaining after in situ hybridization. After probe development, neuroepithelial explants and control embryos were washed in PBT and embedded in 5\% agarose in distilled water. They were then cut at $50 \mu \mathrm{m}$ with a vibratome (Vibratome 1000 Plus). The sections were blocked in 20\% bovine serum albumin (BSA) in PBT for $20 \mathrm{~min}$ at room temperature and then incubated $\mathrm{ON}$ at $4^{\circ} \mathrm{C}$ with a monoclonal antibody antiactive caspase- 3 at 1/500 (Pharmingen, San Diego, CA). After being washed in PBT, they were incubated with an anti-mouse antibody conjugated to Alexa-488 at $1 / 200$ (Molecular Probes, Eugene, OR) for $2 \mathrm{hr}$ at RT. The samples analyzed were taken from the central area of the explants to standardize results, thus avoiding the damaged tissue of the periphery.

To detect DNA synthesis, BrdU incorporation into cell nuclei was determined by the addition of BrdU to the culture medium at a final concentration of $5 \mu \mathrm{M}$ for 1 hr at the end of the organotypic culture. The presence of incorporated BrdU was performed as previously described for mesencephalic neuroepithelial explants (Gato et al., 2005). Five explants were analyzed for each culture condition. To detect early neuronal differentiation, we monitored $\beta 3$-tubulin (Tuj-1) expression as previously described for mesencephalic neuroepithelial explants (Gato et al., 2005). Five explants were analyzed for each culture condition. Photomicrographs of sectioned material were taken using a Dialux 20 microscope (Leica). Digital images were taken with a CCD Coolpix 4500 camera (Nikon) and were assembled in Photoshop.

\section{RESULTS}

\section{Neuroepithelial Gene Expression in Mesencephalic Explants Lacking the IsO}

To test the autonomy of neuroepithelial gene expression in mesencephalic explants lacking any known organizing center and to check whether E-CSF contributes to the regulation and/or maintenance of neuroepithelial gene expression, we cultured mesencephalic explants lacking the $\mathrm{IsO}$ for $24 \mathrm{hr}$, i.e., from $\mathrm{HH} 20$ to $\mathrm{HH} 23$, in three sets of experiments: 1) explants cultured only with basal medium (DMEM:F12), 2) explants cultured with E-CSF-supplemented medium, and 3) explants cultured with FGF2-supplemented medium. Because of peripheral damage to explants during experimental manipulations to keep them attached to the filter, gene expression and cell behavior on the periphery of the tissue were not evaluated (see Materials and Methods).

For in situ hybridization, we used three different riboprobes for corresponding genes whose expression domains in the brain vesicles had been previously described: $f g f 8$, which in both $\mathrm{HH} 20$ control explants and $\mathrm{HH} 23$ control embryos is expressed in the $\mathrm{IsO}$, to check whether the absence of an organizer caused the formation of new ectopic organizing centers that may influence mesencephalic gene expression; ot 2 , which in both kind of controls is expressed in the neuroepithelium of the mesencephalon, to check whether these cells maintained their normal pattern of mesencephalic gene expression; and shh, which in controls is expressed in the ventral midline of the neuroectoderm, to check putative changes in dorsoventral patterning of gene expression.

First, we analyzed whether the absence of an organizing center in these mesencephalic explants triggered the formation of new ectopic IsOs. Mesencephalic explants cultured either with basal medium or with ECSF- or FGF2-supplemented medium did not express any trace of fgf 8 (Fig. 1A), as with $\mathrm{HH} 20$ and $\mathrm{HH} 23$ controls, in which the expression of this gene is restricted to the IsO (see Fig. 2A1 for control mesencephalic + Is O explant showing $f g f 8$ expression in the Is $\mathrm{O}$ at the beginning of the culture).

Then, we checked whether mesencephalic neuroectodermal explants maintained a normal pattern of otx2 expression in the absence of the Is O. No mesencephalic explant cultured just with basal medium expressed any trace of otx2 (Fig. 1B). However, corresponding explants cultured with E-CSF- or FGF2-supplemented medium did express otx2, although, unlike the case with $\mathrm{HH} 20$ control mesencephalic explants and $\mathrm{HH} 23$ control embryos, some dorsal mesencephalic neuroectodermal patches did not express otx2. Although all analyzed explants showed patches not expressing ot 2 , the extension and location of the patches within the explant can vary slightly. These results suggest that otx 2 expression in mesencephalic tissue lacking the $\mathrm{IsO}$ is not autonomous, at least in the absence of E-CSF.

Finally, we looked for changes in dorsoventral patterning of gene expression in these dorsal mesencephalic explants. No dorsal mesencephalic explants cultured just with basal medium expressed any trace of shh (Fig. 1C), whereas, surprisingly, corresponding explants cultured with E-CSF-supplemented medium had some patches of shh expression, unlike controls, which showed shh expression restricted to the ventral midline. Although all analyzed explants cultured with E-CSF-supplemented 


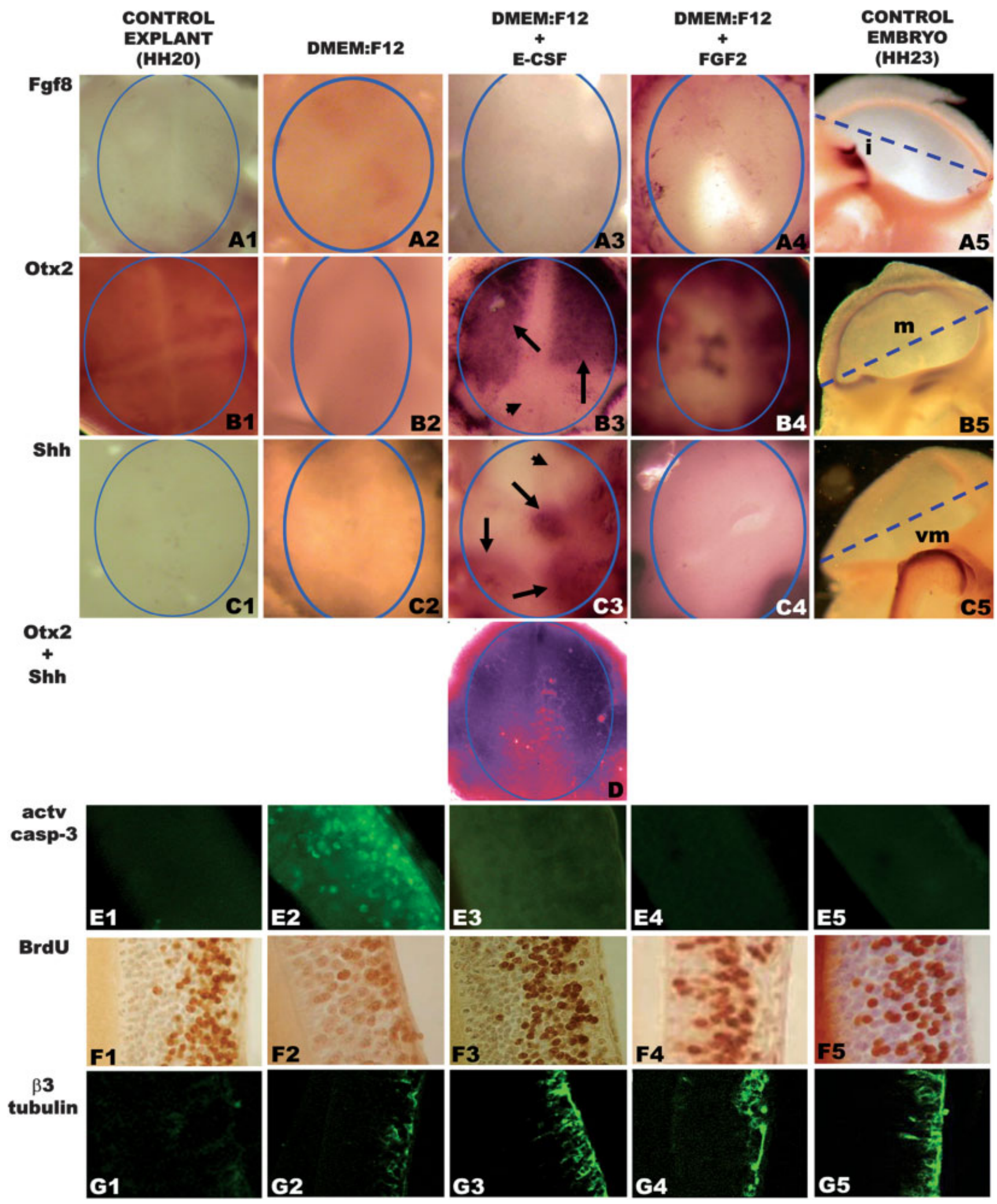

Figure 1. 
medium showed patches of shh expression, the extension and location of these patches within the explant can also vary slightly. Patches that did not express ot 2 matched patches expressing shh, as revealed by double in situ hybridization (Fig. 1D). Explants cultured with FGF2supplemented medium did not show any trace of shh expression (Fig. 1C4), suggesting that E-CSF may contain molecules that specifically trigger shh ectopic expression in these explants that lack the IsO.

It had previously been reported that E-CSF is involved in neuroectodermal cell survival in vitro, so we verified whether this cellular parameter was impaired in these mesencephalic explants. All explants used for in situ hybridization were immunostained with an antibody to active caspase 3 after probe development. As expected, explants cultured just with basal medium had more active caspase 3 cells that were positive than explants cultured with E-CSF- or FGF2-supplemented medium, which were similar to control (Fig. 1E). This suggests that the lack of otx2 expression in the mesencephalic explants cultured just with basal medium may be due to impaired cell survival.

However, not all neuroectodermal cells had impaired survival behavior. Therefore, we next checked whether in these explants there were still a significant number of functionally active cells that maintained other basic cellular processes, e.g., DNA synthesis and neural differentiation, because it was thought that these functionally active cells might express the monitored genes. As shown in Figure 1F,G, explants cultured with basal medium had a significant number of neuroepithelial cells that maintained DNA synthesis, as detected by bromodeoxyuridine (BrdU) incorporation and that were engaged in the process of primary neurogenesis, as detected by $\beta 3$ tubulin immunostaining, though these were fewer than in explants cultured with E-CSF- or FGF2-supplemented medium and fewer than in HH23 controls. Taken together, these results suggest that gene expression in mesencephalic explants lacking the $\mathrm{IsO}$ is not completely autonomous and that it depends at least in part on the presence of E-CSF, although, according to the observed disturbances in otx 2 and shh expression domains, other factors are needed to ensure a completely normal pattern of gene expression.

\section{Neuroepithelial Gene Expression in Mesencephalic + IsO Explants}

To test whether the morphogenetic activity of the IsO was sufficient to ensure a normal pattern of gene expression in mesencephalic explants, and to determine whether the absence of the $\mathrm{IsO}$ in the above-described mesencephalic explants accounts for the presence of nonotx2-expressing patches, we cultured mesencephalic + $\mathrm{IsO}$ neuroectodermal explants with either basal medium or E-CSF-supplemented medium also for $24 \mathrm{hr}$, from $\mathrm{HH} 20$ to $\mathrm{HH} 23$.

First, we analyzed whether in these explants the IsO maintained its normal morphogenetic activity by monitoring $f g f 8$ expression, because its gene product is known to be the active diffusible molecule for this organizing center. No mesencephalic $+\mathrm{IsO}$ explants cultured just with basal medium had any trace of $f g f 8$ expression (Fig. 2A), whereas these same explants cultured with E-CSF-supplemented medium had $f g f 8$ expression restricted to the $\mathrm{IsO}$ area, as $\mathrm{HH} 20$ control explants and HH23 control embryos did (see Fig. 1A5 for an HH23 control embryo).

With respect to otx2 expression, no mesencephalic + IsO explants cultured just with basal medium expressed any trace of this gene (Fig. 2B), whereas the same explants cultured with E-CSF-supplemented medium showed a completely normal pattern of expression, as did control (see Fig. 1B5 for a $\mathrm{HH} 23$ control embryo). We then tested whether these dorsal explants also showed ectopic shh expression domains, as reported for mesencephalic explants lacking the IsO. Neither mesencephalic $+\mathrm{IsO}$ explants cultured with basal medium nor those cultured with E-CSF-supplemented medium showed any trace of shh expression (Fig. 2 C), the same as controls (see Fig. 1C5 for a HH23 control embryo). This suggests that the lack of $\mathrm{IsO}$ in these explants accounts for the reported differences in otx2 and shh expression domains in control embryos and, thus, that E-CSF collaborates with the $\mathrm{IsO}$ to maintain the expression of these genes.

There were no previous reports on the role of ECSF in neuroectodermal cell survival in organotypic cul-
Fig 1. A-G: Mesencephalic neuroectodermal explants cultured with basal medium (DMEM:F12) or E-CSF- or FGF2-supplemented medium for $24 \mathrm{hr}$, from $\mathrm{HH} 20$ to $\mathrm{HH} 23$, compared with HH20 control explants and HH23 control embryos developed in ovo. The culture medium is indicated at the top of each column, and either the probe used for the hybridization or the detected molecule is shown at left. All explants and the mesencephalon of control embryos were immunostained with an antibody to active caspase 3 (actv casp-3) after probe development to view apoptosis. E1-5 are typical cross-sections of neuroectoderm for each culture condition or for controls to show the presence of apoptotic cells. F1-5 are typical cross-sections of neuroectoderm showing the presence of DNA-synthesizing cells under the appropriate culture conditions. G1-5 are typical cross-sections of neu- roectoderm showing early neuronal differentiation under the appropriate culture conditions. In all cross-sections, the basal pole of the neuroectoderm is to the right and the apical pole to the left. Dashed line in control embryos developed in ovo (A5, B5 and C5) indicates the craneocaudal sectioning line of the explants. The corresponding explants are shown in a coronal view. Cranial is to the top. D shows a double in situ hybridization to otx2 (for NBT/BCIP development) and shh (for fast development viewed with a rhodamine filter set). The circle in the whole-mount explants indicates the central area of the explants, because the damaged tissue of the periphery should not be taken into account. Arrows indicate areas of gene expression. Arrowheads indicate patches not expressing otx2. i, Isthmus; $\mathrm{m}$, mesencephalon; vm, ventral midline. 


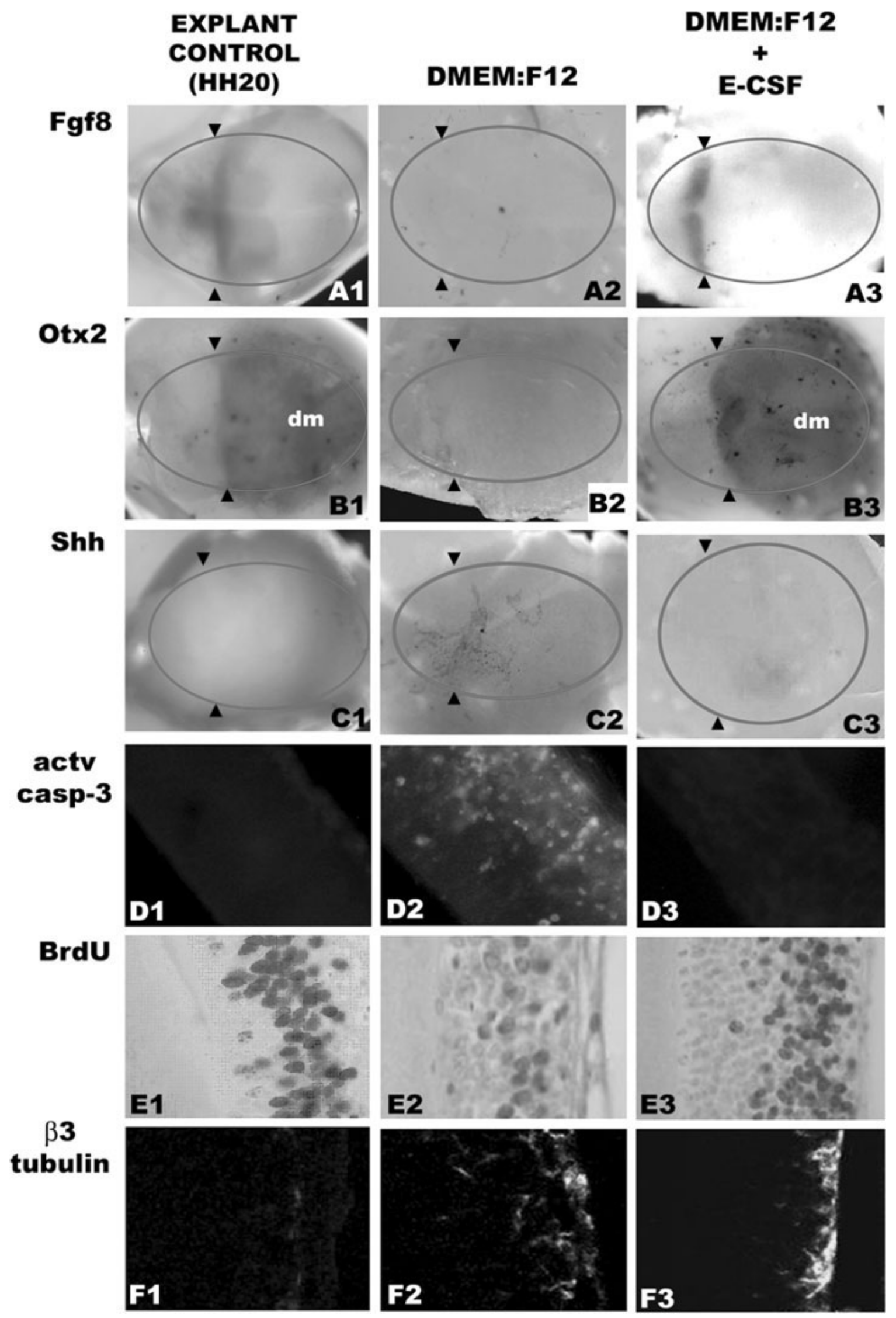

Figure 2. 
tures of dorsal mesencephalic explants including the $\mathrm{IsO}$, so we checked whether this cellular parameter was impaired. Mesencephalic $+\mathrm{IsO}$ explants cultured just with basal medium had more active caspase 3-positive cells than explants cultured with E-CSF-supplemented medium or controls (Fig. 2D; see Fig. 1E5 for a HH23 control embryo). Again, this suggested that the lack of $f_{g} f 8$ and otx 2 expression in the mesencephalic $+\mathrm{IsO}$ explants cultured just with basal medium may be due to impaired cell survival. With respect to DNA synthesis and neural differentiation, a significant number of neuroepithelial cells in explants cultured with basal medium maintained DNA synthesis and were engaged in the process of primary neurogenesis, although there were fewer of these than of explants cultured with E-CSF-supplemented medium and HH23 controls (see Fig. 1F5, G5 for HH23 control embryos).

Finally, we analyzed whether the presence of FGF8, the active diffusible molecule for IsO morphogenetic activity, was sufficient to maintain normal mesencephalic gene expression or, alternatively, to induce the ectopic expression of other typically IsO-expressed genes, e.g., pax2 and en1. Mesencephalic explants lacking the IsO were cultured with either FGF8-supplemented medium or E-CSF + FGF8-supplemented medium at $50 \mathrm{ng} / \mu \mathrm{l}$ for $24 \mathrm{hr}$, from $\mathrm{HH} 20$ to $\mathrm{HH} 23$. For in situ hybridization, we used three different riboprobes for genes whose expression domains had been previously described: otx2 (see above), pax2, and en1, which in HH20 control explants and $\mathrm{HH} 23$ control embryos are expressed in the IsO.

No mesencephalic explants cultured with either FGF8-supplemented medium or E-CSF + FGF8-supplemented medium expressed any trace of otx2 (Fig. 3A), unlike controls. Similarly, no mesencephalic explants cultured with FGF8-supplemented medium showed any pax2 or en1 expression (Fig. 3B,C), but, conversely, explants cultured with E-CSF + FGF8-supplemented medium did exhibit patches of pax 2 and en 1 expression. In HH20 and $\mathrm{HH} 23$ controls, pax2 expression was restricted to the $\mathrm{IsO}$ (Fig. 3B), and en 1 was expressed at $\mathrm{HH} 20$ in both the mesencephalon and the $\mathrm{IsO}$ and was restricted to the $\mathrm{IsO}$ at $\mathrm{HH} 23$ (Fig. 3C).

Surprisingly, when we checked cell survival by active caspase 3 immunostaining in all these explants, there were more apoptotic cells in explants cultured with both FGF8- and E-CSF + FGF8-supplemented medium than in controls (Fig. 3D). However, these explants also had a significant number of neuroepithelial cells that maintained DNA synthesis and that were engaged in the process of primary neurogenesis (Figs. 3E,F), which may account for the neuroepithelial cells expressing pax2 and en 1 in explants cultured with E-CSF + FGF8-supplemented medium, although there were fewer of them than of explants cultured with E-CSF-supplemented medium and HH23 controls (see Fig. 1F3, G3 for explants cultured with E-CSF-supplemented medium).

It is known that overexpression of $f g f 8$ leads to increased cell death in telencephalic explants, so we cultured mesencephalic explants with several different concentrations of FGF8, i.e., $5 \mathrm{ng} / \mu \mathrm{l}$ and $0.5 \mathrm{ng} / \mu \mathrm{l}$, in E-CSF-supplemented medium (Fig. 4). As FGF8 concentration decreased, otx 2 expression progressively increased, and, conversely, pax 2 and en 1 expression domains decreased. Accordingly, the number of active caspase 3positive cells also decreased. Taken together, these results suggest that the remaining functionally active neuroectodermal cells, at least in explants cultured with E-CSFsupplemented medium, and despite the fact that they may not be completely healthy, do indeed express typical neuroectodermal genes, insofar as they expressed pax2 and en 1 under the induction of FGF8 in the presence of E-CSF.

\section{DISCUSSION}

In this paper, by using an organotypic tissue culture technique for neuroectodermal explants, we demonstrate that E-CSF collaborates with the IsO in the regulation of mesencephalic neuroectodermal gene expression. Mesencephalic and mesencephalic + Is $\mathrm{O}$ explants cultured just with basal medium do not express either of the typically expressed mesencephalic or IsO genes analyzed, i.e., otx 2 and $f g f 8$, respectively, even though significant numbers of neuroepithelial cells maintain their basic cellular functions, as seen by DNA synthesis and neural differentiation. Mesencephalic explants cultured with E-CSF-supplemented medium do not express $f g f 8$, as expected for explants lacking the Is $\mathrm{O}$, and the expression domains of otx2 and shh are different from those of control embryos: otx 2 is not expressed in some neuroepithelial patches of the mesencephalon, and shh is ectopically expressed in the patches that do not express otx2. Interestingly, mesencephalic explants cultured with FGF2-supplemented medium show the same pattern of
Fig 2. A-F: Mesencephalic + $\mathrm{IsO}$ neuroectodermal explants cultured with either basal medium (DMEM:F12) or E-CSF-supplemented medium for $24 \mathrm{hr}$, from $\mathrm{HH} 20$ to HH23, compared with HH20 control explants. Control embryos developed in ovo are in Figure 1. The culture medium is indicated at the top of each column, and either the probe used for the hybridization or the detected molecule is at left. The explants are shown in a coronal view. Craneal is to the right. D1-3 are typical cross-sections of neuroectoderm showing the presence of apoptotic cells. E1-3 are typical cross-sec- tions of neuroectoderm showing the presence of DNA-synthesizing cells under the appropriate culture conditions. F1-3 are typical crosssections of neuroectoderm showing early neuronal differentiation under the appropriate culture conditions. In all cross-sections, the basal pole of the neuroectoderm is to the right and the apical pole to the left. The circle indicates the central area of the explants, because the damaged tissue of the periphery should not be taken into account. Arrowheads indicate the position of the isthmus. dm, Dorsal mesencephalon. 

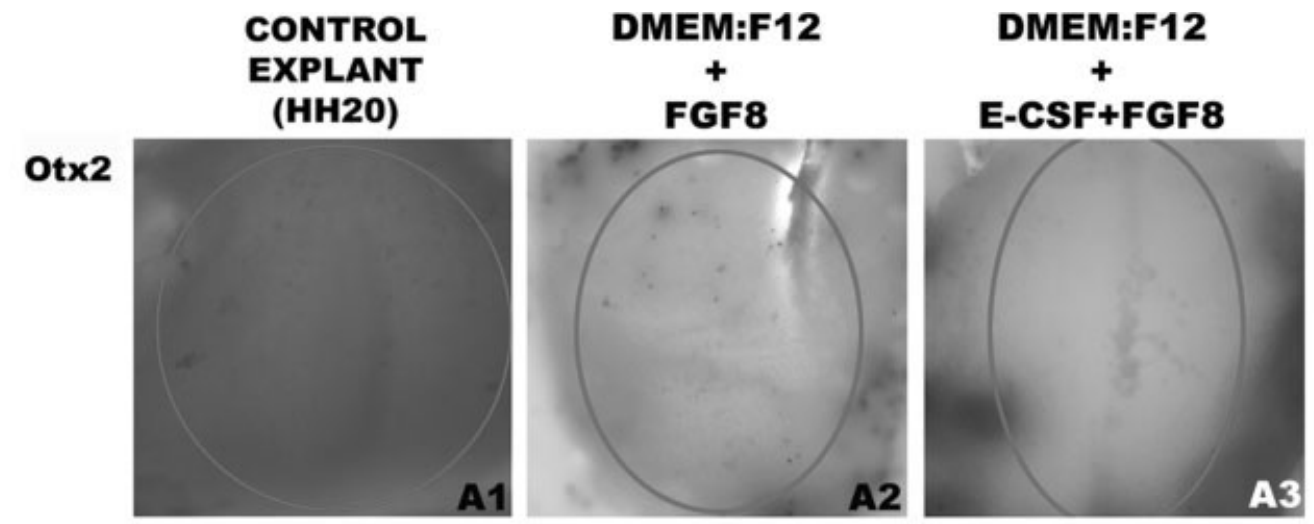

\section{CONTROL}

EMBRYO

(HH23)
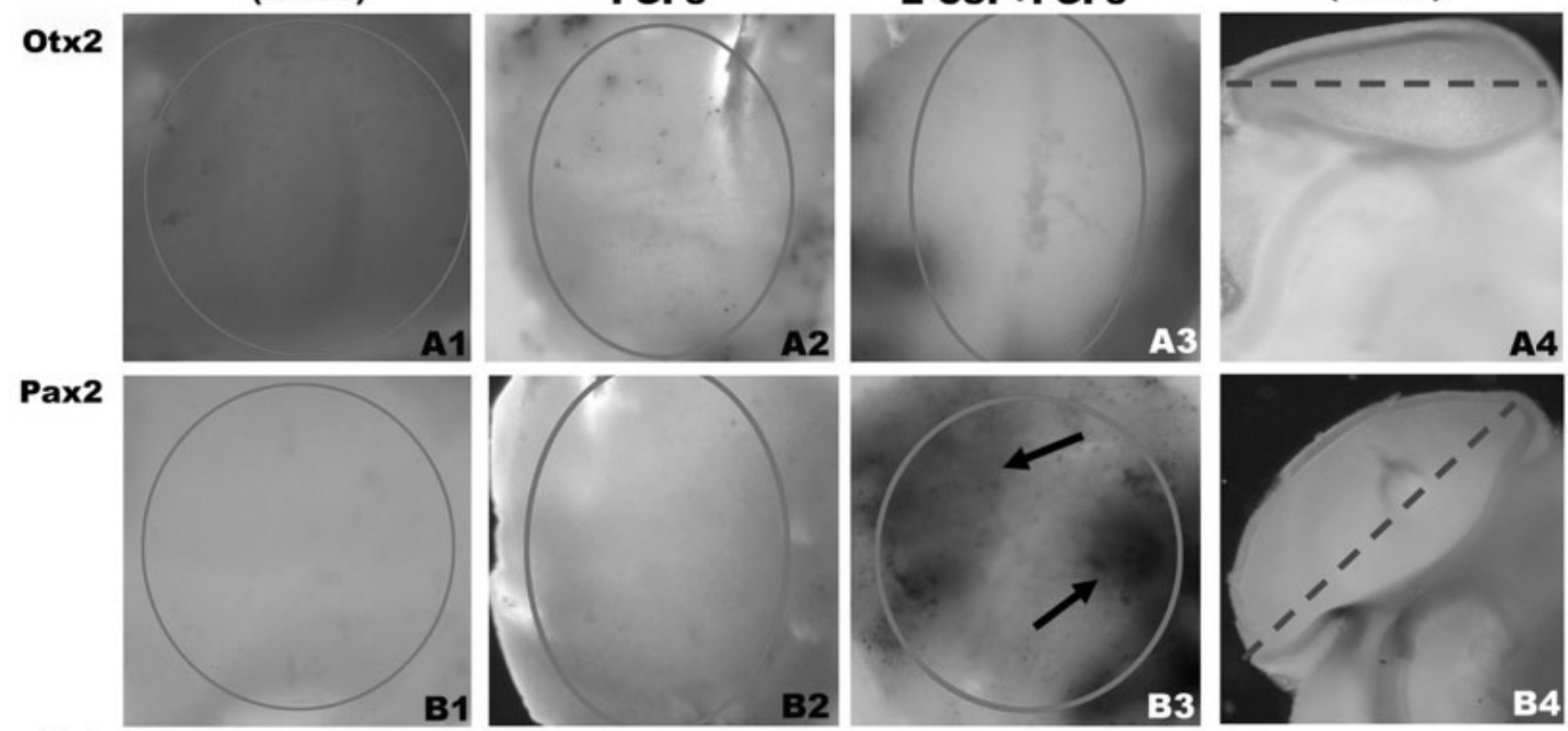

En1
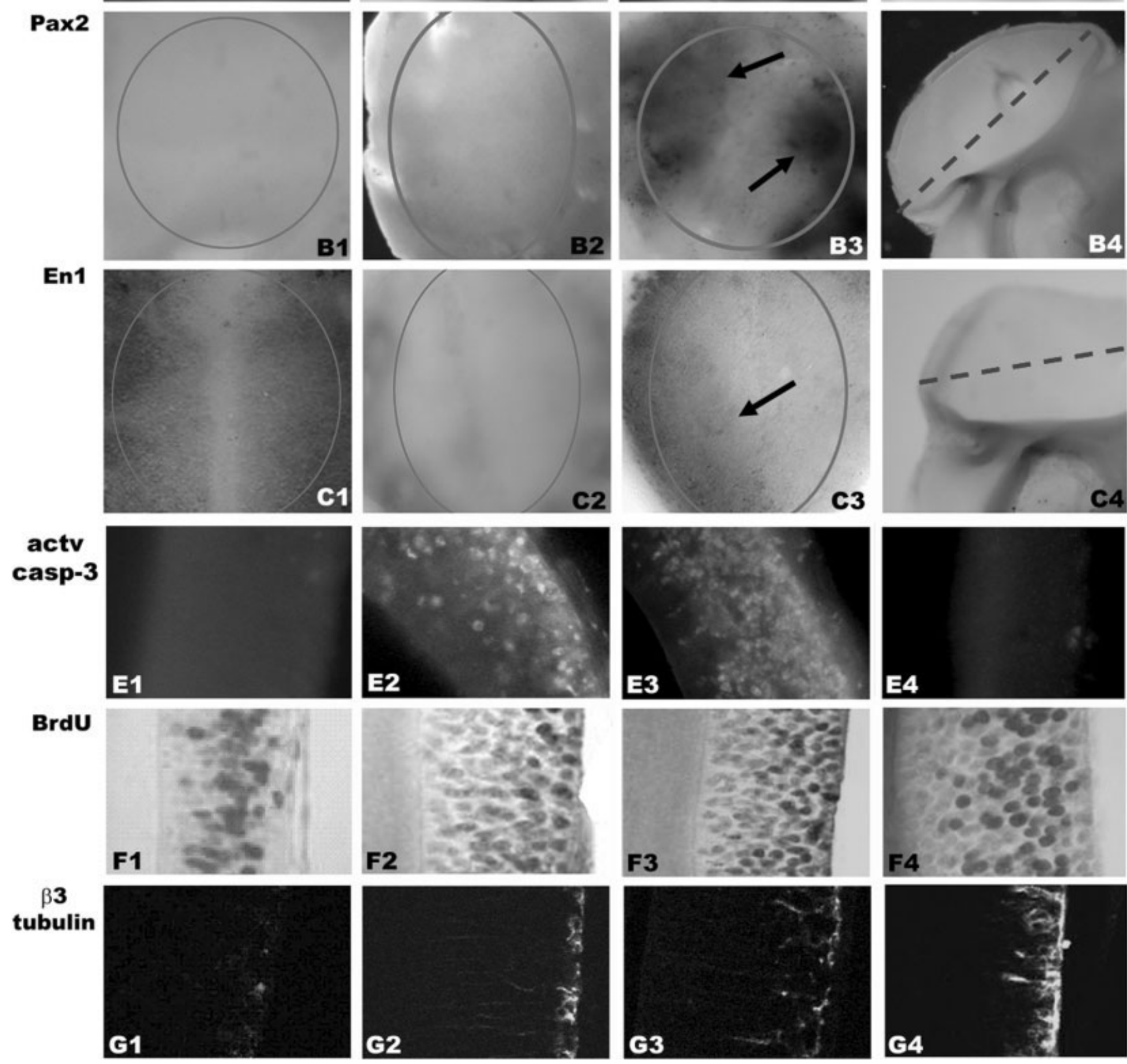

\section{E4}
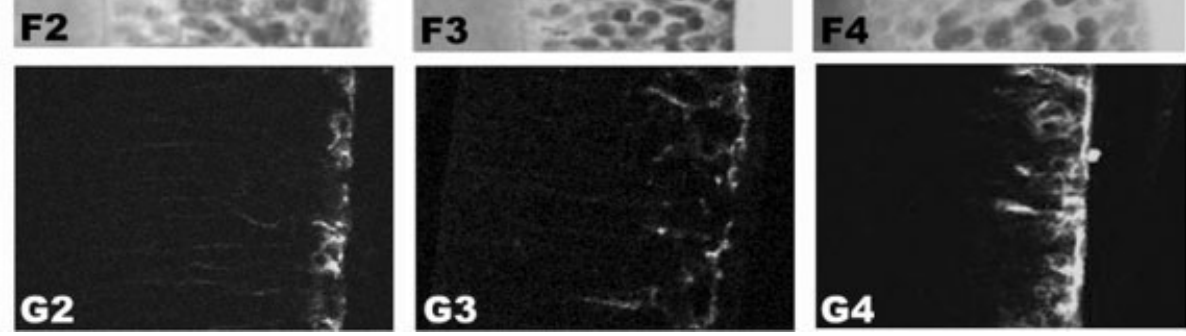

Figure 3. 
otx2 expression but do not express shh. Conversely, the expression pattern of fof 8 , otx 2 , and shh in explants comprising both mesencephalic and $\mathrm{Is} \mathrm{O}$ neuroectoderm cultured with E-CSF-supplemented medium mimics the pattern for control embryos developed in ovo. Finally, FGF8 induces the ectopic expression of pax2 and en 1 in the mesencephalon in the presence of E-CSF and represses otx2 expression, in a concentration-dependent manner. Overall, our results suggest that E-CSF has a role in the maintenance of neuroepithelial gene expression.

\section{E-CSF Influences Neuroepithelial Gene Expression}

Experimental evidence that neuroepithelial cell survival, replication, and differentiation are maintained by E-CSF in mesencephalic neuroectodermal explants has recently been provided (Gato et al., 2005). It has been suggested that E-CSF, which is in close contact with the apical pole of the neuroectodermal cells at the analyzed developmental stages, contains key molecules involved in the control of these cell processes. Consequently, it plays a relevant role in the development of the embryonic brain in vivo. In this way, E-CSF has a complex protein composition (Dziegielewska et al., 1980, 1981). By using 2Delectrophoresis techniques, Western blot, and sequencing analysis, we identified at least 30 proteins in E-CSF, including some proteins known to be involved in neuronal development in systems other than E-CSF, such as $\mathrm{N}$-cadherin, some members of the apolipoprotein family and retinol carriers, and FGF2, among others (Gato et al., 1998; Parada et al., 2005). To test their individual roles in brain development, functional analysis of the gene products identified within E-CSF is clearly needed. It has also been suggested that in adults CSF plays a key role as a fluid way to deliver diffusible signals to the ependyma, whose apical pole is also in close contact with CSF and, thus, to influence the behavior of determined brain parenchyma cells (Nicholson, 1999; Alvarez-Buylla and Garcia-Verdugo, 2002; Tramontin et al., 2003).

To check whether E-CSF as a whole is also involved in the regulation of neuroepithelial gene expression, we first analyzed the gene expression autonomy of the neuroepithelium. It is known that some kinds of explants, e.g., palate explants, are able to grow in vitro in basal medium in the absence of any specific additive, such as fetal serum (Cuervo et al., 2002). Our results show that the behavior of the neuroectoderm with respect to gene expression is not autonomous, insofar as both mesencephalic and mesencephalic + IsO explants cultured just with basal medium or with FGF8-supplemented medium, the active diffusible molecule for isthmic morphogenetic activity (Martínez et al., 1999; Shamin et al., 1999; Joyner et al., 2000; Martínez, 2001; Puelles et al., 2003, 2004), do not express either of the analyzed genes, i.e., otx 2 and $f g f 8$ for the mesencephalon and $\mathrm{IsO}$, respectively, unlike explants cultured with ECSF-supplemented medium. In explants cultured with basal medium, the survival of some neuroepithelial cells is impaired, a result that is corroborated by recent reports evaluating this cell behavior parameter and quantifying it with the same organotypic culture technique (Gato et al., 2005). Thus, it may be thought that this impaired cell background accounts at least partially for the lack of otx 2 and $f_{g} f 8$ expression.

It is worth noting that mesencephalic explants cultured with E-CSF + FGF8-supplemented medium (at $50 \mathrm{ng} / \mu \mathrm{l}$ ) also have a significant number of apoptotic cells, similar to the number for explants cultured with just basal medium. They also have a significant number of functionally active cells. Unlike explants cultured with just basal medium, the explants cultured with E-CSF + FGF8-supplemented medium do exhibit ectopic expression of pax2, which suggests that the functionally active cells that remain in these organotypic cultures, despite the fact that they may not be completely healthy, express typical mesencephalic genes. The fact that these explants, which are cultured in a medium containing E-CSF, are able to express the analyzed genes, whereas explants cultured only in basal medium are not, despite the fact that both exhibit a similar number of active caspase 3-positive cells, indicates that E-CSF is needed to allow cells thought to be functionally active for gene expression. To distinguish between a mechanistic role for E-CSF in cell survival and a direct role in activating gene expression, the results of explants cultured with FGF2-supplemented medium must be considered (see below).

The ectopic induction of pax2 and en 1 expression-genes that in control embryos at a developmental stage equivalent to that for the end of the culture are normally expressed in the $\mathrm{Is} \mathrm{O}$-indicates that the presence of FGF8 in the culture medium in the presence of E-CSF mimics the induction of ectopic IsOs reported in
Fig 3. A-G: Mesencephalic neuroectodermal explants cultured either with FGF8-supplemented medium or with E-CSF + FGF8-supplemented medium at $50 \mathrm{ng} / \mu \mathrm{l}$ for $24 \mathrm{hr}$, from HH20 to HH23, compared with $\mathrm{HH} 20$ control explants and $\mathrm{HH} 23$ control embryos developed in ovo. The culture medium is indicated at the top of each column, and either the probe used for the hybridization or the detected molecule is at left. D1-4 are typical cross-sections of neuroectoderm showing the presence of apoptotic cells. E1-4 are typical cross-sections of neuroectoderm, showing the presence of DNA-synthesizing cells under the appropriate culture conditions. F1-4 are typ- ical cross-sections of neuroectoderm, showing early neuronal differentiation under appropriate culture conditions. Dashed line in control embryos developed in ovo (A4, B4 and C4) indicates the craneocaudal sectioning line of the explants. The corresponding explants are shown in a coronal view. Cranial is to the top. In all cross-sections, the basal pole of the neuroectoderm is to the right and the apical pole to the left. The circle indicates the central area of the explants, because the damaged tissue on the periphery should not be included. Arrows indicate areas of gene expression. i, Isthmus; m, mesencephalon. 


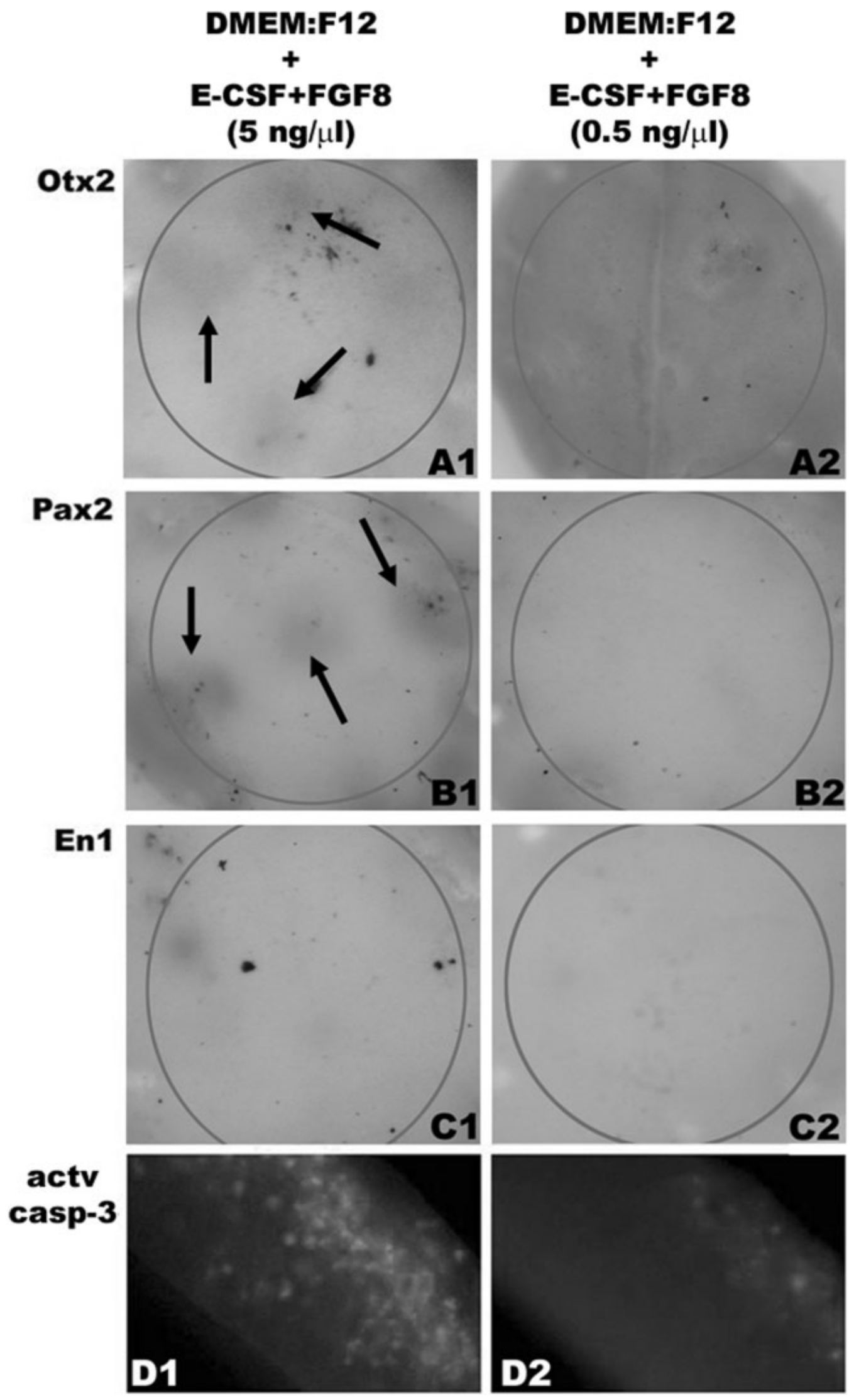

Figure 4. 
experiments performed in vivo by the implantation of heparin beads carrying FGF8 (Liu et al., 1999; Martínez et al., 1999). This result contributes to the validation of this organotypic tissue culture technique, in that it reproduces in vitro the same inductive and repressive effects on gene expression domains as reported in vivo.

Regarding the significant increase in the number of apoptotic cells in mesencephalic explants cultured with E-CSF + FGF8-supplemented medium at $50 \mathrm{ng} / \mu \mathrm{l}$, it is known that overexpression of FGF8 leads to increased cell death in telencephalic explants, and it has been suggested that a tightly regulated level of FGF8 is critical to maintain its function in mesencephalic/metencephalic patterning (Meyers et al., 1998; Chi et al., 2003; Storm et al., 2003). Our results support these suggestions, in that mesencephalic explants cultured with E-CSF + FGF8-supplemented medium either at $5 \mathrm{ng} / \mu \mathrm{l}$ or at $0.5 \mathrm{ng} / \mu \mathrm{l}$ do exhibit a progressive decrease in the number of apoptotic cells, a progressive decrease in the induction of the ectopic expression of pax 2 and en 1 and, thus, a progressive increase of otx 2 expression.

More interesting for the purposes of this study, when mesencephalic explants are cultured with FGF2supplemented medium, a growth factor that is known to be one of the main factors involved in regulating the proliferation and differentiation of neural precursors at early stages of development (Tropepe et al., 1999; Panchision and McKay, 2002), the explants' basic cell behavioral parameters (i.e., cell survival, proliferation, and neural differentiation) are similar to those for explants cultured with E-CSF-supplemented medium (Martín et al., 2005). These mesencephalic explants are also able to express otx2, much as do explants cultured with E-CSF-supplemented media. Conversely, however, they do not express shh ectopically. This indicates that E-CSF contains a molecule (or molecules) that trigger ectopic shh expression in the absence of IsO. Thus, the facts that 1) cells that are thought to be functionally active in explants cultured just with basal medium do not express either otx 2 or $f g f(2)$ explants cultured with E-CSF-supplemented medium do express these genes, 3) FGF2 maintains the basic cell behavioral parameters as well as otx2 expression in these organotypic cultures just as E-CSF does but conversely is unable to trigger the ectopic expression of shh as E-CSF does, and 4) functionally active cells in explants cultured with E-CSF + FGF8-supplemented medium also express pax2 and en 1 all support the hypothesis that the role of E-CSF in neuroepithelial gene expression is not restricted to the maintenance of cell survival but also contributes to neuroepithelial gene expression.

\section{E-CSF Collaborates With the IsO To Regulate the Patterning of Mesencephalic Gene Expression}

As stated above, mesencephalic explants lacking the IsO cultured with E-CSF-supplemented medium show small disturbances in shh and otx2 expression domains. Shh, which in control embryos is expressed in the ventral midline of the neuroectoderm, but never in lateral or dorsal mesencephalon (Echelard et al., 1993; Bueno et al., 1996a), is ectopically expressed in some patches of dorsal mesencephalon, the ones that do not have otx2 expression. It is known that, to control the pattern and development of the cephalic vesicles, most genes involved in these processes interact with each other. In this regard, otx2 exerts a dose-dependent repressive effect that coordinates proper positioning of shh (Puelles et al., 2003, 2004). It has been reported that conditional mouse mutants in which otx 2 expression domain is dorsally reduced show a dorsally enlarged expression domain for shh (Puelles et al., 2003). Thus, the presence of patches that do not express otx 2 may account for the release of the repressive effect on shh expression.

Moreover, we also show that mesencephalic $+\mathrm{IsO}$ explants cultured with E-CSF-supplemented medium have a completely normal pattern of gene expression. Thus, fof 8 expression is restricted to the IsO; otx 2 expression is detected all along the mesencephalon but not in the $\mathrm{IsO}$, and shh expression is not detected at all. As discussed above, to control the pattern and development of the cephalic vesicles, most of the genes involved in these processes interact with each other. Thus, and in addition to the dose-dependent repressive effect exerted by otx 2 to coordinate proper positioning of shh in the ventral midline, it also represses $f g f 8$ expression in the mesencephalon (Martínez et al., 1999; Joyner et al., 2000; Martínez, 2001; Puelles et al., 2003, 2004). FGF8 is known to be one of the active diffusible molecules in IsO morphogenetic activity (together with Wnt1; Wilkinson et al., 1987; Nusse and Warmus, 1992) and contributes to the patterning of gene expression in the mid- and hindbrain, inducing the expression of en 1, en2, pax2, and pax5 and repressing otx2 (Liu et al., 1999; Ye et al., 2001).

The completely normal pattern of expression of otx 2, fof 8 , and shh in the mesencephalic + Is O explants cultured with E-CSF-supplemented medium indicates that, in these organotypic cultures, the Is $\mathrm{O}$ maintains its normal morphogenetic activity in the presence of E-CSF and that these explants mimic the reported interactions for these genes, as in embryos developed in ovo. Taking
Figure 4. A-D: Mesencephalic neuroectodermal explants cultured with E-CSF + FGF8-supplemented medium at either $5 \mathrm{ng} / \mu \mathrm{l}$ or $0.5 \mathrm{ng} / \mu \mathrm{l}$ for $24 \mathrm{hr}$, from $\mathrm{HH} 20$ to $\mathrm{HH} 23$. The culture medium is indicated at the top of each column, and either the probe used for the hybridization or the detected molecule is at left. D1,2 are typical cross-sections of neuroectoderm showing the presence of apoptotic cells. The explants are shown in a coronal view. Cranial is to the top. In all cross-sections, the basal pole of the neuroectoderm is on the right, and the apical pole at left. The circle indicates the central area of the explants, becuase the damaged tissue on the periphery should not be included. Arrows indicate areas of gene expression. 
together all the reported results, we can conclude that, in vitro, E-CSF collaborates with the IsO to regulate the expression of some characteristic neuroectodermal genes during early stages of CNS development and that the survival factors contained within the E-CSF are needed by the $\mathrm{IsO}$ to exert its morphogenetic activity. However, because E-CSF is able to induce shh ectopic expression in the absence of $\mathrm{IsO}$, and known trophic factors involved in regulating the proliferation and differentiation of neural precursors at early stages of development (i.e., FGF2) are not, we suggest that this collaboration goes beyond the strict function of the maintenance of neuroepithelial cell survival exerted by E-CSF. It is tempting to speculate that the same collaboration occurs during in vivo development.

\section{ACKNOWLEDGMENTS}

The authors thank the referees for their comments and suggestions, which have improved the ease of reading this paper as well as making it more informative and more technically sound. This work was supported by Ministerio de Sanidad y Consumo, Instituto de Salud Carlos III grants 02/0915 (to D.B.) and 02/0961 (to A.G.), cofinanced by European Community FEDER; Regional Government of Castilla y León grants VA049/04 and VA17/03 (to A.G.); Generalitat de Catalunya grant GRQ93-1044 (to Prof. Jaume Baguñà); and a Generalitat de Catalunya FI-IQUC Predoctoral Fellowship (to C.P.).

\section{REFERENCES}

Alvarez-Buylla A, García-Verdugo JM. 2002. Neurogenesis in adult subventricular zone. J Neurosci 22:629-634.

Bueno D, Skinner J, Abud H, Heath JK. 1996a. Spatial and temporal relationships between $\mathrm{Shh}, \mathrm{Fg} f$, and $\mathrm{Fg} f 8$ gene expression at diverse signalling centres during mouse development. Dev Dyn 207:291-299.

Bueno D, Skinner J, Abud H, Heath JK. 1996b. Double in situ hybridisation on mouse embryos for detection of overlapping regions of gene expression. TIG 12:385-387.

Chi C, Martínez S, Wurst W, Martin G. 2003. The isthmic organizer signal FGF8 is required for cell survival in the prospective midbrain and cerebellum. Development 130:2633-2644.

Crossley PH, Martin GR. 1995. The mouse Fgf8 gene encodes a family of polypeptides and is expressed in regions that direct outgrowth and patterning in the developing embryo. Development 121:439-451.

Crossley PH, Martinez S, Martin GR. 1996. Midbrain development induced by FGF8 in the chick embryo. Nature 380:66-68.

Cuervo R, Valencia C, Chandraratna RAS, Covarrubias L. 2002. Programmed cell death is required for palate shelf fusion and is regulated by retinoic acid. Dev Biol 245:145-156.

Dziegielewska KM, Evans CAN, Fossan G, Lorscheider FL, Malinowska DH, Mollgard K, Reynolds ML, Saunders NR, Wilkinson S. 1980. Proteins in cerebrospinal fluid and plasma of fetal sheep during development. J Physiol 300:441-455.

Dziegielewska KM, Evans CAN, Lai PCW, Lorscheider FL, Malinowska DH, Mollgard K, Saunders NR. 1981. Proteins in cerebrospinal fluid and plasma of fetal rats during development. Dev Biol 83:193-200.

Echelard Y, Epstein DJ, St.-Jacques B, Shen L, Mohler J, McMahon JA, McMahon AP. 1993. Sonic hedgehog, a member of a family of putative signaling molecules, is implicated in the regulation of CNS polarity. Cell 75:1417-1430.
Garda AL, Echevarría D, Martínez S. 2001. Neuroepithelial co-expression of Gbx2 and Otx2 precedes Fgf8 expression in the isthmic organizer. Mech Dev 101:111-118.

Gato A, Alonso MI, Moro JA, Martín P, Barbosa E. 1998. Presence of FGF-2 in chick embryo neural tube fluid. Eur J Anat 2:185-186.

Gato A, Martín P, Alonso MI, Martín C, Pulgar MA, Moro JA. 2004. Analysis of cerebro-spinal fluid protein composition in early developmental stages in chick embryos. J Exp Zool 301:280-289.

Gato A, Moro JA, Alonso MI, Bueno D, De La Mano A, Martín C. 2005. Embryonic cerebrospinal fluid regulates neuroepithelial survival, proliferation and neurogenesis in chick embryos. Anat Rec (in press).

Hamburger V, Hamilton HL. 1951. A series of normal stages in the development of the chick embryo. J Morphol 88:49-92.

Joyner AL, Liu A, Millet S. 2000. Otx2, Gbx2 and Fgf8 interact to position and maintain a mid-hindbrain organizer. Curr Opin Cell Biol 12: 736-741.

Li JY, Joyner AL. 2001. Otx2 and Gbx2 are required for refinement and not induction of mid-hindbrain gene expression. Development 128: 4979-4991.

Liu A, Losos K, Joyner AL. 1999. FGF8 can activate Gbx2 and transform regions of the rostral mouse brain into a hindbrain fate. Development 126:4827-4838.

Martí E, Takada R, Bumcrot DA, Sasaki H, McMahon AP. 1995. Distribution of Sonic hedgehog peptides in the developing chick and mouse embryo. Development 121:2537-2547.

Martín C, Bueno D, Alonso MI, Moro JA, Callejo S, Parada C, Martín P, Gato A. 2005.FGF2 play a key role in embryonic cerebrospinal fluid trophic properties over neuroepithelial stem cells. Submitted for publication.

Martínez S. 2001. The isthmic organizer and brain regionalization. Int J Dev Biol 44:367-371.

Martínez S, Crossley PH, Cobos I, Rubenstein JL, Martín GR. 1999. FGF8 induces formation of an ectopic isthmic organizer and isthmocerebellar development via a repressive effect on Otx2 expression. Development 126:1189-1200.

Mashayekhi F, Draper CE, Bannister CM, Pourghasem M, Owen-Lynch PJ, Miyan JA. 2002. Deficient cortical development in the hydrocephalic texas (H-Tx) rat, a role for CSF. Brain 125:1859-1874.

Meyers EN, Lewandoski M, Martin GR. 1998. An Fgf8 mutant allelic series generated by Cre- and Flp-mediated recombination. Nat Genet 18:136-141.

Miyan JA, Nabiyouni M, Zendah M. 2003. Development of the brain: a vital role for cerebrospinal fluid. Can J Physiol Pharmacol 81:317-328.

Nicholson C. 1999. Signals that go with the flow. Trends Neurosci 22: 143-145.

Nusse R, Warmus HE. 1992. Wnt genes. Cell 69:1073-1087.

Owen-Lynch PJ, Draper CE, Mashayekhi F, Banniste CM, Miyan JA. 2003. Defective cell cycle control underlies abnormal cortical development in the hydrocephalic texas rat. Brain 126:623-231.

Panchision DM, McKay RDG. 2002. The control of neural stem cells by morphogenic signals. Curr Opin Genet Dev 12:478-487.

Parada C, Aparicio M, Gato A, Bueno D. 2005. Proteome analysis of embryonic cerebrospinal fluid in chick embryos. Proteomics (in press).

Placzek M, Yamada T, Tessier-Lavigne M, Jessell T, Dodd J. 1991. Control of dorsoventral pattern in vertebrate neural development, induction and polarizing properties of the floor plate. Development 2: 105-122.

Placzek M, Jessell TM, Dodd J. 1993. Induction of floor plate differentiation by contact-dependent, homeogenetic signals. Development 117: 205-218.

Puelles E, Acampora D, Lacroix E, Signore M, Annino A, Tuorto F, Filosa S, Corte G, Wurst W, Ang SL, Simeone A. 2003. Otx dosedependent integrated control of antero-posterior and dorso-ventral patterning of midbrain. Nat Neurosci 6:453-460. 
Puelles E, Annino A, Tuorto F, Usiello A, Acampora D, Czerny T, Brodski C, Ang SL, Wurst W, Simeone A. 2004. Otx2 regulates the extent, identity and fate of neuronal progenitor domains in the ventral midbrain. Development 131:2037-2048.

Roelink H, Augsburger A, Heemskerk J, Korzh V, Norlin S, Ruiz i Altaba A, Tanabe Y, Placzek M, Edlund T, Jessell TM. 1994. Floor plate and motor neuron induction by vhh-1, a vertebrate homolog of hedgehog expressed by the notochord. Cell 76:761-775.

Shamim H, Mahmood R, Logan C, Doherty P, Lumsden A, Mason I. 1999. Sequential roles for Fgf4, En1 and Fgf8 in specification and regionalisation of the midbrain. Development 126:945-959.

Storm E, Rubenstein JL, Martin G. 2003. Dosage of FGF8 determines whether cell survival is positively or negatively regulated in the developing forebrain. Proc Natl Acad Sci U S A 100:1757-1762.

Toresson H, Potter SS, Campbell K. 2000. Genetic control of dorsoventral identity in the telencephalon: opposing roles for Pax6 and Gsh2. Development 127:4361-4371.

Tramontin AD, García-Verdugo JM, Lim DA, Alvarez-Buylla A. 2003. Postnatal development of radial glia and the ventricular zone (VZ): a continuum of the neural stem cell compartment. Cereb Cortex 13:580587.
Tropepe V, Sibilia M, Ciruna BG, Rossant J, Wagner EF, van der Kooy D. 1999. Distinct neural stem cells proliferate in response to EGF and FGF in the developing mouse telencephalon. Dev Biol 208:166-188.

Vaccarino FM, Schwartz ML, Raballo R, Nilsen J, Rhee J, Zhou M, Doetschman T, Coffin JD, Wyland JJ, Hung YT. 1999a. Changes in cerebral cortex size are governed by fibroblast growth factor during embryogenesis. Nat Neurosci 2:246-253.

Vaccarino FM, Schwartz ML, Raballo R, Rhee J, Lyn-Cook R. 1999b. Fibroblast growth factor signaling regulates growth and morphogenesis at multiple steps during brain development. Dev Biol 44:179-201.

Wilkinson DG, Bailes JA, McMahon AP. 1987. Expression of the protooncogene int-1 is restricted to specific neural cells in the developing mouse embryo. Cell 50:79-88.

Yamada T, Placzek M, Tanaka H, Dodd J, Jessell TM. 1991. Control of cell pattern in the developing nervous system: polarizing activity of the floor plate and notochord. Cell 64:635-647.

Ye W, Bouchard M, Stone D, Liu X, Vella F, Lee J, Nakamura H, Ang SL, Busslinger M, Rosenthal A. 2001. Distinct regulators control the expression of the mid-hindbrain organizer signal FGF8. Nat Neurosci 4:1175-1181. 